\title{
Object relatives made easy: A cross-linguistic comparison of the constraints influencing young children's processing of relative clauses
}

\author{
Evan Kidd \\ University of Manchester, Manchester, $U K$ \\ Silke Brandt, Elena Lieven and Michael Tomasello \\ Max Planck Institute for Evolutionary Anthropology, Leipzig, Germany
}

\begin{abstract}
We present the results from four studies, two corpora and two experimental, which suggest that English- and German-speaking children (3;1-4;9 years) use multiple constraints to process and produce object relative clauses. Our two corpora studies show that children produce object relatives that reflect the distributional and discourse regularities of the input. Specifically, the results show that when children produce object relatives they most often do so with (a) an inanimate head noun, and (b) a pronominal relative clause subject. Our experimental findings show that children use these constraints to process and produce this construction type. Moreover, when children were required to repeat the object relatives they most often use in naturalistic speech, the subject-object asymmetry in processing of relative clauses disappeared. We also report cross-linguistic differences in children's rate of acquisition which reflect properties of the input language. Overall, our results suggest that children are sensitive to the same constraints on relative clause processing as adults.
\end{abstract}

The acquisition of relative clause (RC) structures is an important milestone in language acquisition, since it suggests that children have command of one

\footnotetext{
Correspondence should be addressed to Evan Kidd, School of Psychological Sciences, The University of Manchester, Oxford Road, Manchester M 13 9PL, UK.

E-mail: evan.j.kidd@manchester.ac.uk

This research was in part supported by a postdoctoral fellowship to the first author from the Max Planck Institute for Evolutionary Anthropology. We would like to thank Anna Roby and Susanne Grassman for help in testing and coding, and Franklin Chang, Paul Bloom and two anonymous reviewers for helpful comments. Portions of this research were presented at the $19^{\text {th }}$ Annual CUNY Conference on Human Sentence Processing.
}

(C) 2007 Psychology Press, an imprint of the Taylor \& Francis Group, an Informa business http://www.psypress.com/lcp

DOI: 10.1080/01690960601155284 
of the defining characteristics of natural languages: recursion. The past literature on the acquisition of relative clauses, in particular data from experimental studies, has reported mixed results. Explanations for these patterns of data have attributed to children processing strategies that are not found in adults, suggesting a discontinuity between child and adult parsing strategies (e.g., Tavakolian, 1981). In the current paper we argue that such explanations are misguided, and that there is no need to hypothesise discontinuities between the child and adult parsing systems. We present four studies that concentrate on two of the most frequent relative clause types: subject- and object relative clauses, as in (1) and (2).

(1) This is the dog [that chased the cat].

(2) This is the dog [that the cat chased].

Sentence (1) is a subject relative clause; the head noun the dog occupies the subject role in the relative clause (in brackets). Sentence (2) is an object relative clause; the dog occupies the object role in the relative clause. Previous research testing both adults and children has found that object relatives are more difficult to process than subject relatives, a result that has either been explained by the argument that object relatives are more syntactically complex (e.g., Friedmann \& Novogrodsky, 2004; Miyamoto \& Nakamura, 2003), or by the suggestion that they are more cognitively demanding to process (e.g., Gibson, 1998). Our data show that when children are tested on object relatives that they most often say and hear, this subject/object asymmetry disappears, just as in studies of adult sentence processing (Mak, Vonk, \& Schriefers, 2002, 2006; Reali \& Christiansen, in press). We interpret the results to suggest that children are sensitive to the same constraints on object relative formation as are adults. Importantly, the data suggest that young children are sensitive to the distributional frequencies of complex structures, and that they make use of this statistical information in the acquisition process.

The paper has the following structure. We first review the child language data on the acquisition of relative clauses, and conclude that current explanations for the acquisition of this family of structures are inadequate. We then review linguistic and adult psycholinguistic literature on subject and object relative clauses, and argue that that the subject/object asymmetry observed in child language research is due to children being tested on object relatives that do not follow the discourse and semantic constraints that lead to object relative formation, resulting in children being tested on object relatives they rarely say or hear. We then present four studies, two corpora and two experimental, that show English- and German-speaking children do not show additional difficulty processing object relatives when these constraints are satisfied. We interpret these findings to suggest that 
(i) children are sensitive to the same constraints on relative clause formation as are adults, and (ii) distributional frequency information plays an important role in the acquisition of parsing strategies.

\section{THE ACQUISITION OF RELATIVE CLAUSES}

Early experimental work on the acquisition of relative clauses suggested that children under 5 years possessed little knowledge of the recursive properties of language (e.g., Sheldon, 1974; Tavakolian, 1981). These studies presented children with sentences like the subject (3) and object relatives (4) below, and required children to act them out using toy props.

(3) The dog [that chased the cat] jumped over the cow.

(4) The cow [that the horse bumped] stood on the goat.

The results from these early studies were far from systematic, largely because children were asked to act out the sentences in the absence of a supporting discourse context and the appropriate felicity conditions that lead to the use of a relative clause as a restrictive modifier (Hamburger \& Crain, 1982). Subsequent research that presented test sentences in the appropriate contexts showed that children have an emerging knowledge of relative clause constructions, but that they do not gain full competence over these types of relatives until age 5 (Córrea, 1995; Kidd \& Bavin, 2002, for a review see Kidd, 2003).

Studies investigating children's knowledge of relative clauses using the act out methodology have been criticised for unnecessarily complicating the child's task and, in particular, for testing children on sentences they would rarely hear (Diessel \& Tomasello, 2005). Subsequent experimental studies have aimed to reduce the task demands placed on children (e.g., Arnon, 2005). These studies report a uniform pattern of results across a range of languages. Namely, just like adults (e.g., Gibson, 1998), children perform better on subject relatives than on object relatives. Some have suggested that this effect is due to children having problems with syntactic derivation, specifically, movement (e.g., Friedmann \& Novogrodsky, 2004). However, the results from other studies suggest that movement-based accounts cannot explain the full range of results (Arnon, 2005; Diessel \& Tomasello, 2005), and instead point to a processing-based explanation. We briefly review some of this recent literature below.

In two papers Diessel and Tomasello (2000, 2005, see also Diessel, 2004) argued that children acquire the grammar of relative clauses by building upon initially restricted syntactic knowledge. In a naturalistic study (Diessel \& Tomasello, 2000) they showed that English-speaking children's 
early relatives occurred mainly in presentational constructions such as (5) and (6), which consisted of a copular main clause and a RC modifying the main predicate nominal.

(5) Is this something that turn around?

(6) This is the sugar that goes in there.

These early RC constructions are characterised by the fact that they are propositionally simple; they express only one idea despite containing two clauses. Rather than encoding old information, the relative clause contains new information about a focused referent. Diessel and Tomasello (2000) suggested that these early relatives emerge from children's existing knowledge of presentational constructions (e.g., This is an $X$ ) and an emerging knowledge of noun modification. As the children grew older they produced more complex varieties of relative clauses. In particular, although children's early relatives were most often subject-extracted, by age 4 years they were producing proportionally more object-extracted relatives. This was more consistent with their input, since the children heard more object than subject relatives in child-directed speech (Diessel, 2004).

In an experimental study, Diessel and Tomasello (2005) investigated 4year-old English- and German-speaking children's knowledge of relative structures that relativised NPs successively down Keenan and Comrie's (1977) NP-accessibility hierarchy: Subject- (with both transitive and intransitive relative clauses), Object-, Indirect Object-, and Genitive-relatives. The children were tested using the sentence repetition technique (see Lust, Flynn, \& Foley, 1996). Unlike in the act-out studies, only right-branching relatives were tested, since children hardly ever modify the subject NP of the main clause in naturalistic speech. These main clauses were either a presentational construction, as in (6), or a transitive clause. A similar pattern of responding was observed in both language groups. Children performed best on subject relatives, followed by object relatives, indirect object relatives, oblique relatives and, finally, genitive relatives. Diessel and Tomasello argued that children's superior performance on subject relatives reflected a processing effect whereby children prefer to pursue subjectextracted interpretations because they have a preference to build simple structures, which is based upon their considerable experience with simple nonembedded sentences. This is similar to early arguments made by Bever (1970, see also Bates \& MacWhinney, 1982; Slobin \& Bever, 1982; Townsend $\&$ Bever, 2001), who argued that children use a canonical sentence schema (NVN) to interpret sentences. Diessel and Tomasello refined this idea slightly: since their results showed that German-speaking children performed similarly to the English-speaking children, and since German does not have a 
canonical NVN schema in subordinate clauses, they argued that children's preference for subject RCs derives from the fact that (a) children expect nouns that encode the thematic role of agent to be relativised, and (b) they also expect the first noun within the RC to encode the agent.

\section{CONSTRAINTS ON OBJECT RELATIVE CLAUSE FORMATION AND PROCESSING}

Two separate, yet related, strands of research suggest that Diessel and Tomasello's (2005) account may be too simple an explanation. The first strand comes from work by Fox and Thompson (1990), who argued for a discourse-based treatment of relative clauses in English. Like Diessel (2004), they showed that object relatives are more frequent than subject relatives in naturalistic speech. However, they showed that object relatives are characterised by the following features: (i) they most often have inanimate heads, and (ii) the subject within the relative clause is most often a discourse-old referent, such as a pronoun. Some examples from Fox and Thompson are given in (7) and (8) (relative clause in brackets).

(7) the problem [I have] is my skin is oily ...

(8) the car [that she borrowed] had a low tyre.

Fox and Thompson argued that these distributional properties of object relatives derive from discourse-based considerations. Subjects are most often animate entities, whereas objects are most often inanimate. Furthermore, according to preferred argument structure (Du Bois, 1987), subjects are most often referred to using pronouns. The pronoun serves a second function in object relatives. As given information, it serves to anchor the head noun in discourse; that is, it links new information expressed by the main clause to information already established in discourse, which is the information contained within the relative clause.

The arguments made by Fox and Thompson (1990) have psycholinguistic support. Studies of adult sentence processing have shown that the difficulty ascribed to object relatives is alleviated when the head noun is inanimate (Mak et al., 2002, 2006; Traxler, Morris, \& Seely, 2002; Traxler, Williams, Blozis, \& Morris, 2005; Weckerly \& Kutas, 1999). Additionally, object relatives are easier to process when they contain a $\mathrm{RC}$ subject that is more accessible than a lexical NP; for instance, when the RC subject is a pronoun or proper noun (Gordon, Hendrick, \& Johnson, 2001; Reali \& Christiansen, in press; Warren \& Gibson, 2002, 2005). The mechanisms underlying these effects have multiple explanations. Although the animacy effect could be explained by semantic plausibility (i.e., inanimate nouns make bad agents), 
the effect has only been observed when the head noun is inanimate (Mak et al., 2002; Traxler et al., 2002), thereby ruling out a similarity-based interference effect (e.g., Gordon et al., 2001). ${ }^{1}$ Furthermore, studies that have tested two animate NPs but manipulated the plausibility of the relationship between the two, as in (9) and (10), still show a processing cost associated with object relatives (e.g., Traxler et al., 2002, Experiment 2).

(9) The policeman that arrested the thief was known to carry a knife.

(10) The thief that the policeman arrested was known to carry a knife.

Since a policeman is more likely to arrest a thief, the semantics of the verb could potentially aid thematic role assignment within the RC and relieve the additional complexity associated with parsing object relatives. However, adult reading time studies in English and German show that this is not the case, although supporting verb semantic information appears to speed up reanalysis (e.g., Schriefers, Friederici, \& Kühn, 1995; Traxler et al., 2002, 2005). That the animacy of the head but not verb semantics is utilised early by the parser makes sense from an incremental perspective. In object relatives in both English and German the subordinate verb is clause final; the parser may have committed to one syntactic analysis by the time the subordinate verb is encountered. However, the animacy of the head noun in combination with the relative pronoun provides a clue about the structure of the upcoming relative clause. Inanimate nouns make bad agents; however, as argued by Mak et al. (2006), from an information structure perspective they are not as topicworthy as animate nouns. Therefore the parser, which must incorporate discoursebased information at some point in the comprehension process, may delay thematic role assignment in anticipation of a likely object relative when the head noun is inanimate. In contrast, when the head noun is animate, the parser is likely to commit to an early subject interpretation because animate heads are more topicworthy and make good subjects.

Following observations made by Bever $(1970,1974)$ and Fox and Thompson (1990), Warren and Gibson (2002) showed that the complexity associated with processing doubly nested object relatives was mediated by the givenness status of the NP subject within the relative clause. Warren and Gibson (2005) showed a similar effect in object cleft sentences. They attribute these findings to the fact that given discourse referents (e.g., pronouns) are

\footnotetext{
${ }^{1}$ Gordon et al. (2001) argued that the difficulty ascribed to object relatives can be attributed to the fact that the NPs participating in the RC have mainly been of the same semantic type animate human NPs. They predict that this causes an interference effect that affects thematic role assignment, and that an object NP that contains two semantically different NPs in any position should alleviate object NP difficulty. Mak et al. (2006) and Traxler et al. (2005) have both shown that the similarity-based approach does not predict patterns of processing difficulty in adults, since, crucially, object relatives that have an animate head and an inanimate RC subject (e.g., the dog that the ball hit) are not easier than object RCs that have semantically identical NPs.
} 
more accessible and therefore require less processing resources to activate, leaving more resources to devote to syntactic processing. Reali and Christiansen (in press) provided an alternative explanation. Following Fox and Thompson (1990) they reported results from a large corpus study that showed object relatives most often occur with personal pronouns in the subject slot of the RC, and that subject relatives most often occur with impersonal pronouns as the $\mathrm{RC}$ object (e.g., it). They then presented selfpaced reading results to show that adult participants processed object relatives more easily than subject relatives when the test sentences contained a personal pronoun as the $\mathrm{RC}$ subject, but that subject relatives were processed more easily when the $\mathrm{RC}$ object was an impersonal pronoun. They interpreted the findings to support a constraint-satisfaction account of parsing whereby the parser registers distributional frequency information (e.g., MacDonald, Pearlmutter, \& Seidenberg, 1994), and uses this information when processing sentences on-line.

No studies examining children's acquisition of relative clauses have manipulated animacy of the head referent or the discourse status of the subject of the RC. When animacy has been manipulated in child language experiments children have shown improved performance (Córrea, 1995; Goodluck \& Tavakolian, 1982); however, these studies manipulated the animacy of the non-relativised role within the relative clause, as in (11), from Goodluck and Tavakolian (1982).

(11) The dog kicks the horse that knocks over the table.

We suggest that the past studies that have observed differences between children's performance on subject- and object-extracted relatives are confounded by the fact that the test sentences fail to satisfy the distributional and discourse facts concerning object relatives. For instance, testing children on object relatives with animate heads may obscure their knowledge of object-extracted relatives because they may not ever hear or produce relativised animate heads in object-extracted relatives.

\section{THE CURRENT RESEARCH}

In the current research we explored English- and German-speaking children's early use of object relative clauses in naturalistic speech. We then tested 3- and 4-year-old English- and German-speaking children on object relatives manipulated for animacy of the head referent and the discourse status of the subject within the relative clause, and compared their performance on object relatives to subject relatives. We aimed to investigate (a) whether the object relatives children produce follow the constraints on object relative formation and processing identified in the linguistic and adult psycholinguistic literature, and (b) whether children use these constraints 
when processing object relatives. We hypothesised that children, like adults, would produce object relative clauses that followed the distributional properties that derive from the discourse pressures of language use. That is, they would produce more object relatives that had (i) an inanimate head, and (ii) a personal pronoun as the subject of the RC. Furthermore, we hypothesised that children would use these cues as constraints on processing when tested in an experimental task. Studies $1 \mathrm{~A}$ and $1 \mathrm{~B}$ report on data from English, and Studies 2A and 2B report on data from German.

\section{STUDY $1 \mathrm{~A}$}

We conducted a corpus analysis in order to identify whether the constraints identified in the adult literature were present in children's speech. We analysed the speech from four English-speaking children from the CHILDES corpus (MacWhinney, 2000): Adam and Sarah from the Brown corpus (Brown, 1973), Nina from the Suppes (1974) corpus, and Peter from the Bloom (1973) corpus. All object relatives were extracted from the corpora and analysed for (i) animacy of the head referent, and (ii) type of NP in the subject slot of the RC. There were 134 Object relatives in total. Overall, 14 $(10.5 \%)$ of the head nouns were clearly animate, $101(75 \%)$ were clearly inanimate, and 19 were ambiguous. Figure 1 shows the distribution of NP types within the subject slot of the RC. We report on six categories of RC subject: 1st person singular and plural pronouns (e.g., I, we), 2nd person singular and plural pronouns (e.g., you), 3rd person singular and plural pronouns (e.g., helshe, they), proper nouns (e.g., Ursula), lexical NPs (e.g., the man), and an 'other' category.

Figure 1 shows that first person (e.g., I, we) and second person pronouns (e.g., you) account for a large percentage $(86.6 \%)$ of the NPs within the

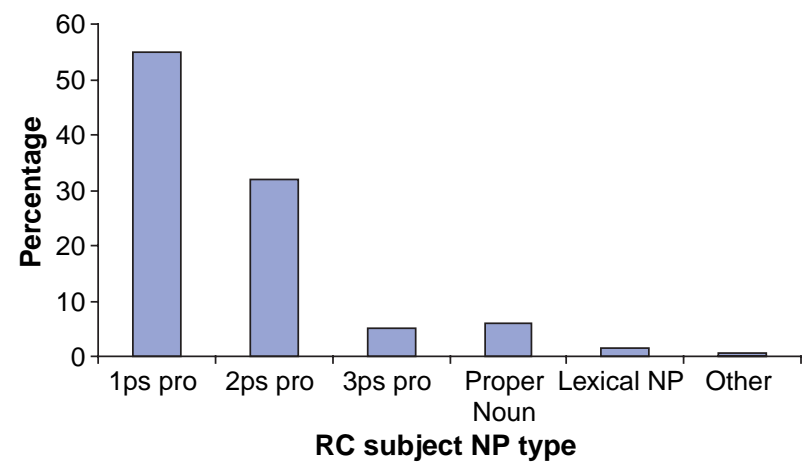

Figure 1. Distribution of NP types within the subject slot of RC in the English data. 
subject slot of the RC. In contrast, lexical NPs made up only $1.5 \%$ of RC subjects. These results suggest that children's early use of object relatives is restricted by the lexico-semantic constraint of animacy of the head NP, and the discourse-based constraint of givenness of the subject NP within the RC. This is consistent with observations of adult speech made by Fox and Thompson (1990). We next report on an experiment that tests whether 3-and 4-year-old English-speaking children are sensitive to these constraints.

\section{STUDY 1B}

We conducted a sentence repetition experiment where we presented 3- and 4year-old children with object relatives manipulated for (i) animacy of the head referent, and (ii) the type of subject NP within the RC (personal pronoun or lexical NP). Children were also presented with subject relatives that were manipulated for the animacy of the head referent. The sentence repetition method is a fairly sensitive measure of children's syntactic knowledge (see Lust, Flynn, \& Foley, 1996). The logic is that children are better able to repeat structures they know best. Potter and Lombardi (1990, 1998) argued that participants apply a semantic analysis of the sentences they are asked to recall, and that when repeating the sentences back they are using the same sentence production mechanism they use when producing regular speech; therefore the sentence repetition method can be considered a good method to investigate young children's sentence processing ability. We hypothesised that children would provide more accurate repetitions of object relatives containing an inanimate head and a personal pronoun as the $\mathrm{RC}$ subject. We also predicted that, when tested on these types of object relatives, the subject-object asymmetry observed in past studies of children's knowledge of RCs would disappear.

\section{Method}

Participants. Fifty-seven $(N=57) 3$ - and 4-year-old children were recruited from nurseries in the Greater Manchester area and from a database of families at the Max Planck Child Study Centre, The University of Manchester. Eight children (seven 3-year-olds and one 4-year-old) were excluded because they did not repeat any of the test sentences correctly. The final sample consisted of twenty-four 3-year-old children (mean $=3 ; 5$, range: $3 ; 1-3 ; 9$ ) and twenty-five 4-year-old children (mean $=4 ; 5$, range: $4 ; 3-4 ; 9$ ). All children were native monolingual speakers of English. None had any known language impairment.

Materials. Twenty-four test sentences were constructed. The first manipulation was the NP relativised within the RC (subject- vs. object 
RCs). The second was the animacy of the head referent (animate vs. inanimate). Finally, the object relatives were manipulated for the type of subject NP within the RC (pronoun vs. lexical NP). The pronouns were always the second person singular indexical pronoun you (see Study 1A). We did not present the sentences in a discourse context; however, this does not mean that the pronoun is infelicitous in this context. Indexical pronouns map onto default roles in any interaction; children could use the experimental context (i.e., an interaction between experimenter and child) to anchor the head noun, provided they are sensitive to this constraint. These manipulations resulted in six sentence categories, as shown in Table 1.

There were four sentences per test condition (see Appendix A). The abbreviations encode the following information: 'Obj' and 'Sub' stand for object and subject RC respectively, ' $A$ ' and 'I' stand for animate and inanimate head noun, and 'NP' and 'Pro' denote the type of the RC subject in object RCs. The main clauses of the sentences were always presentational constructions containing the 3 psg form of the copula. This follows Diessel and Tomasello (2000), who showed that this was the most common main clause to occur with RCs in children's naturalistic speech. Therefore, like Diessel and Tomasello (2005), we did not test centre-embedded RCs.

The test sentences were controlled for length in words and syllables. The sentences were between 11 and 13 words and 12 and 14 syllables in length. Following Diessel and Tomasello (2005), the sentences were matched for length by adding adverbials to the ends of the sentences (e.g., yesterday, last summer) and less frequently by adjectival modification of nominal constituents (e.g., cricket ball). A set of toys that acted as concrete referents for the NPs in the test sentences were used.

Procedure. Children were tested in either a quiet area of their nursery school, or in a laboratory in the Max Planck Child Study Centre. The children were introduced to the experiment as a game where they had to

TABLE 1

Examples of test sentences for each condition in Study 1B

\begin{tabular}{ll}
\hline Condition & \multicolumn{1}{c}{ Sentence } \\
\hline Obj-A-NP & This is the boy that the girl teased at school yesterday. \\
Obj-A-Pro & That is the dog that you stroked in the park yesterday. \\
Obj-I-NP & Here is the food that the cat ate in the kitchen today. \\
Obj-I-Pro & There is the book that you read in the front room last night. \\
Sub-A & Here is the lady that helped the girl at school today. \\
Sub-I & Here is the plant that grew in the garden last summer. \\
\hline
\end{tabular}


repeat what the experimenter said. This was introduced as 'the parrot game', where, just like a parrot, the child would be required to copy the experimenter exactly. The children then completed four practice trials (three simple sentences and one infinitival complement). The practice trials served to introduce the children to the task, and provided an opportunity for the experimenter to provide explicit feedback to the children: if a child did not repeat any of the practice items exactly the experimenter repeated the item until the child did so. The children then moved onto the experiment. The 24 test items were interspersed between 16 filler sentences. These fillers were less demanding sentences that had two functions: (i) to provide children with a wider range of structures so that they would not be primed across trials, and (ii) to provide children with less demanding sentences so that they would not be discouraged by the complex test sentences. The order of presentation of the sentences was pseudorandomised; four orders were used.

Scoring. Following Diessel and Tomasello (2005), children's responses were assigned a score of $1,0.5$, or 0 . A score of 1 was given for an exact repetition. The following modifications of the sentence were permitted: (i) contraction of the main verb to the sentence-initial demonstrative, and (ii) changes that did not radically alter the semantics of the sentence (e.g., changes in tense, number, definiteness, and to the sentence-initial demonstrative). Some children changed the pronoun in the subject slot of the $\mathrm{RC}$ from you to $I$. This was coded as correct, since it suggests that the children understood these test sentences as directed to them. A response was scored 0.5 if it contained a minor deviation from the test sentence. Such deviations included: (i) lexical substitutions (e.g., tree for plant), (ii) omissions of adverbs, adjectives, or determiners. A score of 0 was given if the structure of the test sentence was changed or if the child produced an ungrammatical repetition.

\section{Results}

The data for each child were transcribed and coded according to the specified coding scheme. The data for each sentence type were collated and converted to proportions. The proportion of correct responses for each sentence type for 3- and 4-year-old children are shown in Table 2.

Table 2 shows that, overall, both the 3- and 4-year-old children performed better when object relatives contained inanimate head nouns, and when the $\mathrm{RC}$ subject was a pronoun. Both age groups performed better on subject relatives that contained an animate head referent than when the head was inanimate.

The children's performance on the different types of object relatives was analysed first. Two 2 (Age: 3 - vs. 4-year-olds) $\times 2$ (Animacy of head referent: 
TABLE 2

Proportion of correct responses (and SEs) for each sentence type for the 3- and 4-yearold children in Study 1B

\begin{tabular}{lcccc}
\hline & \multicolumn{4}{c}{ Animacy of the head } \\
\cline { 2 - 5 } & RC subject & Animate & Inanimate & Total \\
\hline 3-year-olds & & & & \\
Object RC & $\mathrm{NP}$ & $.323(.065)$ & $.344(.062)$ & $.333(.06)$ \\
& Pro & $.443(.049)$ & $.599(.055)$ & $.521(.043)$ \\
& Total & $.383(.048)$ & $.471(.049)$ & $.427(.044)$ \\
Subject RC & & $.52(.057)$ & $.36(.048)$ & $.438(.046)$ \\
4-year-olds & & & & \\
Object RC & $\mathrm{NP}$ & $.485(.066)$ & $.54(.064)$ & $.51(.06)$ \\
& Pro & $.535(.064)$ & $.62(.065)$ & $.58(.056)$ \\
Subject RC & Total & $.513(.058)$ & $.578(.056)$ & $.545(.053)$ \\
& & $.71(.057)$ & $.54(.068)$ & $.625(.058)$ \\
\hline
\end{tabular}

Animate vs. Inanimate $) \times 2$ (RC subject type: Pronoun vs. lexical NP) ANOVAs were conducted, one by participants $\left(F_{1}\right)$ and one by items $\left(F_{2}\right)$. The $F_{1}$ analyses were performed on $\log _{10}(x+1)$ transformed data because they were not normally distributed; the $F_{2}$ data were normally distributed and so were not transformed. All subsequent $F_{1}$ analyses are reported on transformed data. There was a significant main effect for the RC subject NP, showing that both age groups performed better on sentences containing pronouns in the subject slot of the RC, $F_{1}(1,47)=12.06, p=.001, M S E=$ .007 , partial $\eta^{2}=.204 ; F_{2}(1,24)=11.40, p=.003, M S E=.013$, partial $\eta^{2}=$ .322. The main effect of animacy was significant by participants and marginal by items, showing that children performed better when sentences contained an inanimate head referent, $F_{1}(1,47)=6.44, p=.015, M S E=.004$, partial $\eta^{2}=.120 ; F_{2}(1,24)=3.25, p=.084, M S E=.013$, partial $\eta^{2}=.119$. The main effect of age was significant by items only, suggesting that the 4year-old children performed better than the 3-year-old children overall, $F_{1}(1$, $47)=2.82, p=.10, M S E=.02$, partial $\eta^{2}=.057 ; F_{2}(1,24)=8.07, p=.009$, $M S E=.013$, partial $\eta^{2}=.252$. No other effects were significant. In particular, there were no interactions with age, indicating that the two age groups did not qualitatively differ from each other. Therefore we did not analyse each individual group's performance separately.

Children's performance on the subject relatives was examined next. We conducted two 2 (Age: 3 - vs. 4-year-olds) $\times 2$ (Animacy of head referent: animate vs. inanimate) ANOVAs, one by participants and one by items. The main effect of animacy was significant, showing that children performed better on sentences containing animate heads than those that contained 
inanimate heads, $F_{1}(1,47)=19.73, p<.001, M S E=.003$, partial $\eta^{2}=.296$; $F_{2}(1,12)=24.49, p<.001, M S E=.005$, partial $\eta^{2}=.671$. The main effect of age was also significant, showing that the 4-year-old children performed better than the 3-year-old children, $F_{1}(1,47)=5.83, p=.02, M S E=.011$, partial $\eta^{2}=.11 ; F_{2}(1,12)=25.64, p<.001, M S E=.005$, partial $\eta^{2}=.681$. The animacy by age interaction was not significant.

Next we compared the children's performance on the subject and object relatives. Overall, the children did not perform better on subject relatives than on object relatives. Multiple Bonferroni comparisons on the ranked means with adjustment for inflation of Type I error rate confirmed this observation (see Table A, Appendix B). The children performed best in the Subj-A and Obj-I-Pro conditions, which did not differ from each other. Performance on both of these conditions was significantly greater than performance in the Subj-I, Obj-I-NP, and Obj-A-NP conditions.

The children's performance on the subject and object relatives suggested that there was a RC-type by animacy interaction. We explored this effect by conducting two 2 (Age: 3 - vs. 4 -year-olds) $\times 2$ (RC type: subject vs. object) by 2 (Animacy of head referent: animate vs. inanimate) ANOVAs, one by participants and one by items. For this analysis we collapsed the variable of $\mathrm{RC}$ subject type for the object relative data. The RC type $\times$ Animacy interaction was significant, $F_{1}(1,47)=23.3, p<.001, M S E=.003$, partial $\eta^{2}=.331 ; F_{2}(1,40)=11.39, p=.002, M S E=.014$, partial $\eta^{2}=.222$. Post hoc Tukey $H S D$ tests showed that this effect was driven by the fact that the children produced significantly more correct subject relatives with animate heads than subject relatives that contained inanimate heads and object relatives that contained animate heads $(p s<.01)$. There was a trend towards the children preferring object relatives with inanimate heads over subject relatives with inanimate heads and object relatives with animate heads (both $p$ s $<.10$ ). The main effect of age was significant, with 4-year-olds performing better overall than the 3-year-olds, $F_{1}(1,47)=4.68, p=.036, M S E=.019$, partial $\eta^{2}=.091 ; F_{2}(1,40)=16.02, p<.001, M S E=.014$, partial $\eta^{2}=.286$.

Error analysis. An advantage of the sentence repetition task is that children make errors that reveal just as much about their processing preferences as do their correct responses. The children made a range of errors, including simply repeating the sentences as simple main clauses and changing the word order of the sentence. It is important to note that many of these errors paraphrased the test sentences such that the children correctly marked the thematic roles of the NPs in the sentence, suggesting that they were applying a meaningful analysis to the test sentence. We were particularly interested in instances where children changed the test sentences to different relative clause structures. Diessel and Tomasello (2005) reported 
that children converted more object relatives to subject relatives than they did subject to object relatives. This was also true in our data, and was by far the most frequent error. Overall, the 3-year-olds made seven subject-toobject conversions, but either fully converted or partially converted an object relative to a subject relative on 102 occasions. Similarly, the 4-year-olds made five subject-to-object RC conversions, but made 70 full or partial object-tosubject RC conversions. A full conversion for the test sentence in (12) is shown in (13).

(12) This is the pen that the boy used at school yesterday.

(13) This is the boy that used the pen at school yesterday.

A partial conversion occurred when the child moved the subordinate verb to be adjacent to the relative pronoun, often deleting the RC subject. An example of this conversion for the test sentence in (14) is shown in (15).

(14) This is the girl that you pushed on the bus this morning.

(15) This is the girl who pushed on the bus this morning.

Sometimes these conversions were grammatical or marginally acceptable, as in (15), and sometimes they were ungrammatical because the subordinate verb was obligatorily transitive. We counted all of these conversions as the same because they are likely to reflect the tendency for children to prefer to produce subject relatives.

We predicted that this tendency to convert object relatives to subject relatives should interact with our manipulations of animacy of the head and the RC subject type. In particular, because animacy is a strong predictor of whether an NP-Relative pronoun combination will be a subject or object RC, we predicted that there would be more object-to-subject RC conversions when the head referent was animate. The manipulation of RC subject type should also affect children's conversions, but potentially not as strongly as the manipulation of animacy. This is because, linearly, the subject of the RC comes after the head noun and should aid in thematic role assignment rather than building of structure. The number of object to subject RC conversions for each object RC condition for the 3- and 4-year-old children is shown in Table 3.

Table 3 shows that both 3- and 4-year-old children provided more objectto-subject RC conversions when the head referent was animate than when it was inanimate. Wilcoxon signed ranked tests collapsing for RC subject type showed that this difference was significant for both $3-(Z=2.91, p=.002)$ and 4-year-old groups $(Z=1.84, p=.033)$. Two more Wilcoxon signed ranked tests tested the difference between sentences manipulated for RC subject type, controlling for animacy. The 3-year-old children provided numerically more object-to-subject RC conversions when the subject of the $\mathrm{RC}$ was a lexical NP, but this difference only approached significance $(Z=$ $1.57, p=.058)$. The manipulation of RC subject type did not affect the 4-year-old children's object-to-subject conversions $(Z=.11, p=.46)$. 
TABLE 3

Number of object-to-subject RC conversions made by 3- and 4-year-old children for each condition in Study 1B

\begin{tabular}{lcccc}
\hline & \multicolumn{4}{c}{ Animacy of the head } \\
\cline { 2 - 5 } & RC subject & Animate & Inanimate & Total \\
\hline 3-year-olds & NP & 38 & 23 & 61 \\
& Pro & 27 & 14 & 41 \\
& Total & 65 & 37 & 102 \\
4-year-olds & & & & \\
& NP & 21 & 14 & 35 \\
& Pro & 22 & 13 & 35 \\
& Total & 43 & 27 & 70 \\
\hline
\end{tabular}

\section{Discussion}

Our results show that the subject-object asymmetry in children's acquisition of relative clauses that has been reported in the literature does not hold across the board. Instead, this effect appears to be moderated by at least two constraints that have been found to affect adults' processing of object RCs: animacy of the head referent and the type of RC subject NP. These two constraints affected the results of the Study $1 \mathrm{~B}$ in different ways.

The constraint of RC subject strongly affected children's correct repetitions but exerted little effect on their object-to-subject RC conversions. In contrast, as indicated by its smaller effect size, the constraint of animacy exerted a smaller effect on children's exact repetitions but led to a greater tendency for children to make object-to-subject RC conversions. These differences suggest that the two constraints play different roles in Englishspeaking children's processing of object relatives.

We suggest that the differential effects of the two constraints can be attributed to their position and role in the sentence. The head noun is encountered first and is followed by the relative pronoun, which signals the need to build a complex NP. There is ambiguity at this point as to which role will be relativised. An animate head noun, which following Mak et al. (2006) is highly topic-worthy and makes a good candidate as an agent, should result in a strong preference for a subject RC. In the present data the effect of animacy was strongest when children converted the object $\mathrm{RC}$ test sentences into subject RCs. Therefore it appears that when the children were producing the test sentences with an animate head they were often overwhelmed by a preference for a subject relative. This preference was less marked when the head referent was inanimate, since an inanimate head is less likely to be an agent and therefore reduces the preference for subject relative formation. 
Additional support for the topicworthy hypothesis comes from children's performance on the subject relatives. Children performed best when the head referent was animate, despite the fact that the test sentences with inanimate heads contained intransitive relative clauses, which Diessel and Tomasello (2005) showed children prefer (when the head is animate). This result suggests that children prefer to produce subject relatives with animate heads, but that when the head referent is inanimate and hence less topicworthy, children's preference for a subject relative is reduced.

In object RCs the RC subject is encountered after the relative pronoun. Within the RC the child's task is to assign the participant roles of the NPs relative to the subordinate verb. This task is complicated in English object $\mathrm{RCs}$ because the word order within the RC is non-canonical. In general, when there are two lexical NPs the child must construct two discourse referents and determine the relationship between them. This is harder than when the sentence contains an indexical pronoun, despite the fact that you is not marked for case. Therefore, our results could be interpreted to be consistent with claims made by Warren and Gibson (2002), who argue that constructing new discourse referents is more computationally complex than accessing anaphoric devices such as pronouns, which when embedded in conversation are discourse-old.

Strictly speaking, however, the lexical NPs in our experiment were not discourse-new referents because the children were presented with toys on which to map the NPs. Therefore their trouble with lexical NP RC subjects is more likely to be attributable to other factors. Personal pronouns are easier to produce because they are both shorter and have higher token frequency than individual lexical NPs, and are more easily referentially grounded. Perhaps most importantly, personal pronouns have distributional privilege as $\mathrm{RC}$ subjects in object relatives, as shown in Study 1A. Following Bybee (2002, 2006), who argued that the representation of constituent structure is highly influenced by high frequency collocations, Reali and Christiansen (in press) suggested that highly frequent patterns within object RCs such as that I VERB become schematicised by the processor such that they are easier to produce, and facilitate processing. Our data are consistent with this proposal, which we discuss further in the General Discussion.

We next present two studies investigating the same constraints on relative formation and processing in German. Relative clauses in German differ from English RCs on a number of dimensions. Morphology plays a much bigger role in the formation and interpretation of German RCs than in English: German relative pronouns are marked for gender, number and case, as are NPs. Unlike in English, German has the same surface structure within both subject and object RCs relative clause because it requires subordinate clause verbs to be clause-final, although the functional order of the nouns differ. 
Therefore German provides a good opportunity to compare children's performance on subject and object RCs. This is because unlike in English, object RC word order is not marked.

\section{STUDY $2 A$}

Study 2A was a corpus study of one German-speaking child's ('Leo') use of object RCs. Leo is a monolingual German boy who at the time of recording was growing up in Leipzig, Germany. His parents speak standard High German. Leo's child-caregiver interactions were recorded for one hour a day for five days per week between the ages of $2 ; 0$ and $3 ; 0$. Between $3 ; 0$ and $5 ; 0$ he was recorded for one hour five days per month. In addition, his parents kept a diary of his early utterances. The data come from a larger study of Leo's acquisition of relative clauses (Brandt, 2004).

Overall, Leo produced a total of 179 object relatives. Four $(2 \%)$ had a clearly animate head referent, and $138(77 \%)$ had a clearly inanimate head. Figure 2 shows the distribution of NP types in the subject slot of the RC.

Figure 2 shows that, in comparison to English, the distribution of NP types is more varied in the German data. Despite this variability, first and second person pronouns still accounted for over half of the data $(62 \%)$. In contrast to the English data, there were many more lexical NPs in the data $(19 \%)$. However, the overall trends are the same: more object relatives were produced when (i) the head referent is inanimate, and (ii) there is a discourseold referent expressed by a pronoun in the subject slot of the RC. From this we conclude that despite the differences between the two languages, production of object RCs is subject to the same constraints. This suggests that the constraints are not language-specific, but have a general-cognitive

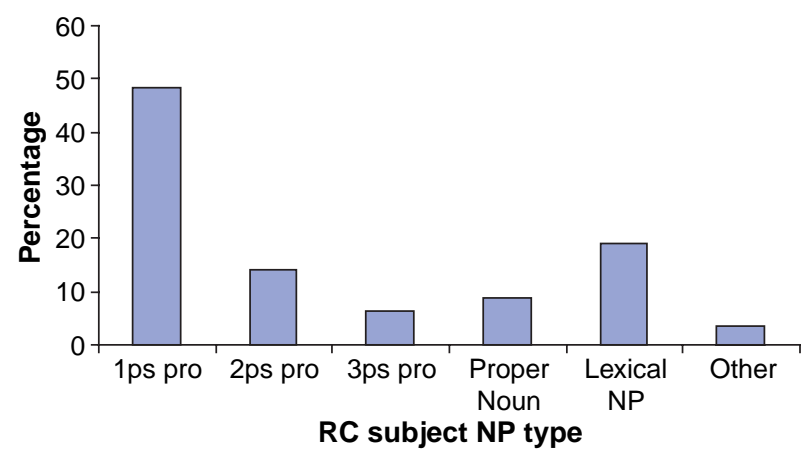

Figure 2. Distribution of NP types within the subject slot of RC in the German data. 
basis that derives from the discourse-functional pressures that lead to the use of object relatives.

\section{STUDY 2B}

We now present a sentence repetition study comparable to Study 1B but with German-speaking 3- and 4-year-old children. As stated above, German RCs differ from English RCs on a number of dimensions. Since German relative pronouns are marked for case, number, and gender, the syntactic role of the head referent within the relative clause is often predictable from the relative pronoun, unlike in English. ${ }^{2}$ The trade off is that children must learn the morphological paradigm for the relative pronoun system, the forms of which share a degree of homonymy with the determiner system. The most important difference between English and German RCs is that German RCs have the same surface word order regardless of whether the subject or object role is relativised within the RC. In this sense the comparison is fairer in German than in English because children do not have to deal with linear distance differences between the two structures.

In their study, Diessel and Tomasello (2005) showed that Germanspeaking children produced a very similar pattern of results to their Englishspeaking children. Most relevant to our study is that the German-speaking children performed significantly worse on object relatives than on subject relatives. Diessel and Tomasello explained this difference by suggesting that children prefer to assign the role of agent to the head noun and, since the word order within subject relatives is agent-patient-verb, there is greater similarity between simple sentences and subject relatives, which are mainly SVO, than between simple sentences and object relatives, which have patientagent-verb word order within the RC. However, since all of their sentences contained animate head NPs, the results could alternatively be explained by Mak et al.'s (2006) topicworthy account, which predicts that the processor will assign agency to a head noun if there is sufficient evidence to expect that noun to occupy the subject role. Following the results of Study 1B, we expected the German-speaking children to be sensitive to the constraints of animacy of the head NP and RC subject type when processing object relatives. That is, we expected our German-speaking participants to provide more correct repetitions of object relatives containing inanimate head NPs and pronominal RC subjects. We also expected children's performance on object relatives to not differ from their performance on subject relatives when these constraints on object relative formation were met.

\footnotetext{
${ }^{2}$ This is actually only true for masculine NPs, as there is greater ambiguity in case marking for feminine and neuter NPs.
} 


\section{Method}

Participants. Sixty $(N=60) 3$ - and 4-year-old children were recruited from nurseries in the Leipzig area. Twelve children were excluded from the final analysis: eight because the children failed to produce any relative clause imitations and four because of experimental error. The final sample consisted of forty-eight children, twenty-four 3-year-olds (mean $=3 ; 6$, range: $3 ; 3-3 ; 9$ ) and twenty-four 4-year-olds (mean $=4 ; 6$, range: 4;3-4;8). All children were native monolingual speakers of German. None had any known language impairment.

Materials. Twenty-four test sentences were constructed by manipulating the exact same variables manipulated in Study 1B. Examples of the test conditions and their English glosses are shown in Table 4 (for the complete list see Appendix C).

All of the German test sentences modified masculine head nouns. This is because in the feminine and neuter form the relative pronouns that mark nominative and accusative case (and therefore subject and object relatives), die and das, are homonymous; there is ambiguity at the relative pronoun as to the syntactic role of the head in the relative clause. This is typically disambiguated by the case role of the next NP; however, we wanted to avoid unnecessarily complicating the children's task. In principle, this means that the German children should be able to identify the relativised role in the RC at the relative pronoun, which the English children cannot do. As in the English study, there were four sentences per test condition (see Appendix B). The main clauses of the sentences were always presentational constructions containing the $3 \mathrm{psg}$ form of the copula. The test sentences were controlled for length in both words and syllables; they were between 10 and 11 words and 14 and 15 syllables long. Therefore they were also as closely matched to the English sentences as possible. A set of toys acted as concrete referents for the NPs in the test and filler sentences.

Procedure and scoring. The procedure and scoring was the same as for Study $1 \mathrm{~B}$.

\section{Results}

The data for each child were transcribed and coded according to the specified coding scheme. The data for each sentence type were collated and converted to proportions. The proportion of correct responses for each sentence type for 3- and 4-year-old children are shown in Table 5.

Table 5 shows that, overall, both the 3- and 4-year-old children performed better when object relatives contained a pronominal $\mathrm{RC}$ subject. Both age 
TABLE 4

Examples of test sentences for each condition in Study 2B (with English glosses)

\begin{tabular}{|c|c|c|c|c|c|c|c|c|c|c|c|}
\hline \multirow{2}{*}{$\frac{\text { Condition }}{\text { Obj-A-NP }}$} & \multicolumn{11}{|c|}{ Sentence } \\
\hline & $\begin{array}{l}\text { Das } \\
\text { that }\end{array}$ & $\begin{array}{l}\text { ist } \\
\text { is }\end{array}$ & $\begin{array}{l}\text { der } \\
\text { the.NOM }\end{array}$ & $\begin{array}{l}\text { Junge } \\
\text { boy }\end{array}$ & $\begin{array}{l}\text { den } \\
\text { who.ACC }\end{array}$ & $\begin{array}{l}\text { der } \\
\text { the.NOM }\end{array}$ & $\begin{array}{l}\text { Mann } \\
\text { man }\end{array}$ & $\begin{array}{l}\text { gestern } \\
\text { yesterday }\end{array}$ & $\begin{array}{l}\text { getroffen } \\
\text { met }\end{array}$ & $\begin{array}{l}\text { hat. } \\
\text { has.3SG }\end{array}$ & \\
\hline Obj-A-Pro & $\begin{array}{l}\mathrm{Da} \\
\text { there }\end{array}$ & $\begin{array}{l}\text { ist } \\
\text { is }\end{array}$ & $\begin{array}{l}\text { der } \\
\text { the.NOM }\end{array}$ & $\begin{array}{l}\text { Mann } \\
\text { man }\end{array}$ & $\begin{array}{l}\text { den } \\
\text { who.ACC }\end{array}$ & $\begin{array}{l}\text { du } \\
\text { you.NOM }\end{array}$ & $\begin{array}{l}\text { gestern } \\
\text { yesterday }\end{array}$ & $\begin{array}{l}\text { im } \\
\text { at:the }\end{array}$ & $\begin{array}{l}\text { Laden } \\
\text { shop }\end{array}$ & $\begin{array}{l}\text { gesehen } \\
\text { seen }\end{array}$ & $\begin{array}{l}\text { hast. } \\
\text { have.2SG }\end{array}$ \\
\hline Obj-I-NP & $\begin{array}{l}\text { Hier } \\
\text { here }\end{array}$ & $\begin{array}{l}\text { ist } \\
\text { is }\end{array}$ & $\begin{array}{l}\text { der } \\
\text { the.NOM }\end{array}$ & $\begin{array}{l}\text { Kuchen } \\
\text { cake }\end{array}$ & $\begin{array}{l}\text { den } \\
\text { that.ACC }\end{array}$ & $\begin{array}{l}\text { der } \\
\text { the.NOM }\end{array}$ & $\begin{array}{l}\text { Mann } \\
\text { man }\end{array}$ & $\begin{array}{l}\text { heute } \\
\text { today }\end{array}$ & $\begin{array}{l}\text { gebacken } \\
\text { baked }\end{array}$ & $\begin{array}{l}\text { hat. } \\
\text { has.3SG }\end{array}$ & \\
\hline Obj-I-Pro & $\begin{array}{l}\mathrm{Da} \\
\text { there }\end{array}$ & $\begin{array}{l}\text { ist } \\
\text { is }\end{array}$ & $\begin{array}{l}\text { der } \\
\text { the.NOM }\end{array}$ & $\begin{array}{l}\text { Pullover } \\
\text { sweater }\end{array}$ & $\begin{array}{l}\text { den } \\
\text { that.ACC }\end{array}$ & $\begin{array}{l}\text { du } \\
\text { you.NOM }\end{array}$ & $\begin{array}{l}\text { heute } \\
\text { today }\end{array}$ & $\begin{array}{l}\text { morgen } \\
\text { morning }\end{array}$ & $\begin{array}{l}\text { gekauft } \\
\text { bought }\end{array}$ & $\begin{array}{l}\text { hast. } \\
\text { have.2SG }\end{array}$ & \\
\hline Sub-A & $\begin{array}{l}\mathrm{Da} \\
\text { there }\end{array}$ & $\begin{array}{l}\text { ist } \\
\text { is }\end{array}$ & $\begin{array}{l}\text { der } \\
\text { the.NOM }\end{array}$ & $\begin{array}{l}\text { Hund } \\
\text { dog }\end{array}$ & $\begin{array}{l}\text { der } \\
\text { that.NOM }\end{array}$ & $\begin{array}{l}\text { den } \\
\text { the.ACC }\end{array}$ & $\begin{array}{l}\text { Vogel } \\
\text { bird }\end{array}$ & $\begin{array}{l}\text { heute } \\
\text { today }\end{array}$ & $\begin{array}{l}\text { im Garten } \\
\text { in:the garden }\end{array}$ & $\begin{array}{l}\text { gejagt } \\
\text { chased }\end{array}$ & $\begin{array}{l}\text { hat. } \\
\text { has.3SG }\end{array}$ \\
\hline Sub-I & $\begin{array}{l}\text { Das } \\
\text { that }\end{array}$ & $\begin{array}{l}\text { ist } \\
\text { is }\end{array}$ & $\begin{array}{l}\text { der } \\
\text { the.NOM }\end{array}$ & $\begin{array}{l}\text { Baum } \\
\text { tree }\end{array}$ & $\begin{array}{l}\text { der } \\
\text { that.NOM }\end{array}$ & $\begin{array}{l}\text { letztes } \\
\text { last }\end{array}$ & $\begin{array}{l}\text { Jahr } \\
\text { year }\end{array}$ & $\begin{array}{l}\text { im } \\
\text { in:the }\end{array}$ & $\begin{array}{l}\text { Garten } \\
\text { garden }\end{array}$ & $\begin{array}{l}\text { gewachsen } \\
\text { grown }\end{array}$ & $\begin{array}{l}\text { ist. } \\
\text { has.3SG }\end{array}$ \\
\hline
\end{tabular}


TABLE 5

Proportion of correct responses (and SEs) for each sentence type for the 3- and 4-yearold children in Study 2B

\begin{tabular}{llccc}
\hline & \multicolumn{4}{c}{ Animacy of the head } \\
\cline { 2 - 5 } & RC subject & Animate & Inanimate & Total \\
\hline 3-year-olds & & & & \\
Object RC & NP & $.052(.04)$ & $.13(.052)$ & $.091(.042)$ \\
& Pro & $.354(.074)$ & $.349(.067)$ & $.352(.068)$ \\
& Total & $.203(.048)$ & $.24(.052)$ & $.221(.048)$ \\
Subject RC & & $.125(.044)$ & $.318(.059)$ & $.221(.046)$ \\
4-year-olds & & & & \\
Object RC & NP & $.255(.04)$ & $.432(.052)$ & $.344(.042)$ \\
& Pro & $.76(.074)$ & $.714(.067)$ & $.737(.068)$ \\
Subject RC & Total & $.508(.048)$ & $.573(.052)$ & $.54(.048)$ \\
& & $.307(.044)$ & $.635(.059)$ & $.471(.046)$ \\
\hline
\end{tabular}

groups also performed better on object relatives when the head referent was inanimate; however, this was only the case when the RC subject was a lexical NP. With respect to the subject relatives, both the 3- and 4-year-old children performed best when the test sentences had an inanimate head.

The children's performance on the different types of object relatives was analysed first. Two 2 (Age: 3- vs. 4-year-olds) $\times 2$ (Animacy of head referent: Animate vs. Inanimate) $\times 2$ ( $\mathrm{RC}$ subject: Lexical NP vs. Pronoun) ANOVAs were conducted, one by participants $\left(F_{1}\right)$ and one by items $\left(F_{2}\right)$. Once again, the $F_{1}$ analyses were performed on $\log _{10}(x+1)$ transformed data because they were not normally distributed; the $F_{2}$ data were normally distributed and so were not transformed. All subsequent $F_{1}$ analyses are reported on transformed data. The children provided significantly more correct responses to object relatives containing inanimate head referents, $F_{1}(1,46)=9.07, p=$ $.004, M S E=.002$, partial $\eta^{2}=.165 ; F_{2}(1,24)=6.73, p=.016, M S E=.006$, partial $\eta^{2}=.219$. The children also provided significantly more correct responses when the object relatives contained a pronominal RC subject, $F_{1}(1$, $46)=60.35, p<.001, M S E=.007$, partial $\eta^{2}=.567 ; F_{2}(1,24)=190.92, p<$ $.001, M S E=.006$, partial $\eta^{2}=.888$. The two main effects were qualified by an Animacy by RC subject interaction, $F_{1}(1,46)=12.89, p=.001, M S E=$ .002 , partial $\eta^{2}=.219 ; F_{2}(1,24)=8.28, p=.008, M S E=.006$, partial $\eta^{2}=$ .256. This effect was driven by the fact that the constraint of animacy appeared to only exert an effect on children's responses when the RC subject was a lexical NP. Finally, there was a main effect of age, showing that the 4year-old children performed significantly better than the 3-year-old children, $F_{1}(1,46)=20.99, p<.001, M S E=.022$, partial $\eta^{2}=.313 ; F_{2}(1,24)=76.11$, $p<.001, M S E=.006$, partial $\eta^{2}=.76$. No other results were significant. 
In particular, as in the English data, there were no interactions with age, indicating that the two age groups did not qualitatively differ from each other. Therefore we did not analyse each individual group's performance separately.

Children's performance on the subject relatives was examined next. We conducted two 2 (Age: 3- vs. 4-year-olds) $\times 2$ (Animacy of head referent: animate vs. inanimate) ANOVAs, one by participants and one by items. There was a significant effect of animacy, showing that the children performed better on sentences that contained inanimate head nouns, $F_{1}(1$, $46)=53.18, p<.001, M S E=.003$, partial $\eta^{2}=.536 ; F_{2}(1,12)=24.65, p<$ $.001, M S E=.014$, partial $\eta^{2}=.673$. There was a significant effect of age, showing that the 4-year-old children performed significantly better than the 3 -year-old children, $F_{1}(1,46)=14.32, p<.001, M S E=.011$, partial $\eta^{2}=$ $.237 ; F_{2}(1,12)=8.77, p=.12, M S E=.014$, partial $\eta^{2}=.422$. The animacy by age interaction was not significant.

Next we compared the children's performance on the subject and object relatives. Multiple Bonferroni comparisons with adjustment for inflation of Type I error rate confirmed the observation that object relatives were not, across the board, more difficult than subject relative (see Appendix B, Table B). The children performed best on the Obj-A-Pro, Obj-I-Pro, and Subj-I conditions, where their performance did not differ from each other. Performance in these three conditions was significantly better than performance on the remaining three conditions: Obj-I-NP, Subj-A, and Obj-A-NP. Additionally, performance in the Obj-I-NP condition was significantly better than performance in the Obj-A-NP condition.

As in Study 1B, we analysed the children's performance on the subject and object relatives to explore whether there was an interaction between RC-type and animacy. Two 2 (Age: 3- vs. 4-year-olds) $\times 2$ (RC-type: subject vs. object) $\times 2$ (Animacy: of head referent: animate vs. inanimate) ANOVAs were conducted, one by participants and one by items. As in Study 1B, for this analysis we collapsed the variable of RC subject type for the object relatives data. There was a significant main effect for animacy, showing that the children performed better on sentences containing inanimate heads, $F_{1}(1$, $46)=65.45, p<.001, M S E=.002$, partial $\eta^{2}=.587 ; F_{2}(1,40)=9.35, p=$ $.004, M S E=.04$, partial $\eta^{2}=.189$. The RC-type by animacy interaction was significant by participants but marginally significant by items, $F_{1}(1$, $46)=24.58, p<.001, M S E=.002$, partial $\eta^{2}=.348 ; F_{2}(1,40)=3.49, p=$ $.069, M S E=.04$, partial $\eta^{2}=.08$. Post hoc Tukey HSD tests showed that the children produced significantly more correct repetitions to subject relatives containing inanimate heads than to subject and object relatives containing animate heads $(p s<.01)$. Additionally, the children produced 
significantly more correct repetitions of object relatives containing inanimate heads than subject relatives containing animate heads $(p<.01)$. A significant main effect for age showed that the 4-year-old children performed better than the 3-year-old children overall, $F_{1}(1,46)=20.79, p<.001, M S E=.019$, partial $\eta^{2}=.311 ; F_{2}(1,40)=12.02, p=.001, M S E=.04$, partial $\eta^{2}=.231$. There were no other significant effects.

Error analysis. As was the case with the English children, the German children made a range of errors. Where the English children made word order errors, the German children made errors in case marking, either by changing the case of the relative pronoun or the case of the RC-internal nonrelativised NPs (or by changing both). The children also provided simple clause paraphrases of the test sentences, and ungrammatical fragments. We only report here on the errors that children made when they produced a relative clause construction; that is, when they changed the test relative clause structure into another relative clause.

The children in both age groups made more object-to-subject than subject-to-object RC conversions. Overall, the 3-year-old children made 10 subject-to-object RC conversions, and 43 unambiguous object-to-subject RC conversions. The 4-year-old children made 24 subject-to-object RC conversions, and 37 unambiguous object-to-subject RC conversions. All subject-toobject conversions were made when the head referent was animate. This is because only the transitive subject RCs contained two NPs where the roles could be reversed. The overall number of conversions is lower than in the English data because the German children produced a lot of ambiguous RC constructions where they marked both the relative pronoun and the first RC internal NP with the incorrect case. For instance, for sentence (16) they produced (17).

(16) der mann, der den hund gestreichelt hat.

The.NOM man that.NOM the.ACC dog patted.

(17) *der mann, den den hund gestreichelt hat.

The.NOM man that.ACC the.ACC dog patted.

The relative clause in (17) is ambiguous because both the head noun (the man) and the RC-internal NP (the dog) are marked for accusative case in the relative clause. In such cases the children did not unambiguously mark agent-patient relations, instead preferring to maintain phonological consistency between the relative pronoun and the determiner of the first NP within the RC. We report on the unambiguous and the ambiguous conversions separately.

The number of unambiguous object-to-subject conversions for each object $\mathrm{RC}$ condition for each age group is shown in Table 6 . 
TABLE 6

Number of object-to-subject RC conversions made by 3- and 4-year-old children for each condition in Study 2B

\begin{tabular}{lcccc}
\hline & \multicolumn{4}{c}{ Animacy of the head } \\
\cline { 2 - 5 } & RC subject & Animate & Inanimate & Total \\
\hline 3-year-olds & NP & 25 & 19 & 44 \\
& Pro & 0 & 0 & 0 \\
& Total & 25 & 19 & 44 \\
4-year-olds & NP & 25 & 11 & 36 \\
& Pro & 1 & 0 & 1 \\
& Total & 26 & 11 & 37 \\
\hline
\end{tabular}

Table 6 shows that, overall, both the 3- and 4-year-old children produced more unambiguous object-to-subject $\mathrm{RC}$ conversions when the test sentence contained a lexical NP RC subject and when the test sentence contained an animate head noun. With respect to the variable of RC subject, Wilcoxon signed tests showed that both the 3- and 4-year-old children provided more object-to-subject conversions when the RC subject was a lexical NP (3-yearolds: $Z=3.43, p<.001$; 4-year-olds: $Z=3.22, p<.001$ ). With respect to the variable of animacy, Wilcoxon signed tests showed that the 4-year-old children produced significantly more object-to-subject conversions when the head noun was animate $(Z=2.66, p=.004)$. Although the 3 -year-old children also produced more object-to-subject conversions when the head noun was animate, this difference was not significant $(Z=1.09, p=.14)$.

The number of ambiguous $\mathrm{RC}$ conversions for each test condition for each age group is shown in Table 7.

Overall, the 3-year-old children made 36 ambiguous conversions on object RC test sentences and 22 on subject RC test sentences. The 4-year-old children made 38 ambiguous conversions on object RC test sentences and 23 on subject RC test sentences. With respect to the object RC sentences, both age groups made more ambiguous conversions when the RC subject was a lexical NP. Wilcoxon signed tests showed these differences to be significant at both age levels (3-year-olds: $Z=3.18, p<.001$; 4-year-olds: $Z=3.33, p<$ $.001)$. The animacy of the head referent did not affect children's ambiguous conversions $(Z s<1)$. With respect to the subject $\mathrm{RCs}$, both age groups made more ambiguous conversions when the head referent was animate, but this was only marginally significant for the 4-year-old group (3-year-olds: $Z=$ $2.00, p=.023$; 4-year-olds: $Z=1.60, p=.055)$. 
TABLE 7

Number of ambiguous $\mathrm{RC}$ conversions for each condition and age group in Study 2B

\begin{tabular}{llccc}
\hline & \multicolumn{4}{c}{ Animacy of the head } \\
\cline { 2 - 5 } & RC subject & Animate & Inanimate & Total \\
\hline 3-year-olds & & & & \\
Object RC & NP & 14 & 18 & 32 \\
& Pro & 3 & 1 & 4 \\
Subject RC & Total & 17 & 19 & 36 \\
4-year-olds & & 16 & 6 & 22 \\
Object RC & NP & & & \\
& Pro & 19 & 18 & 37 \\
Subject RC & Total & 19 & 19 & 38 \\
& & 15 & 8 & 23 \\
\hline
\end{tabular}

\section{Discussion}

The results of Study 2B match up well with the English data reported in Studies $1 \mathrm{~A}$ and $1 \mathrm{~B}$, and with the German corpus data reported in Study $2 \mathrm{~A}$. Like the English children, when processing object relatives the German children were sensitive to the constraints of animacy of the head referent and the RC subject type. In fact, the results from the German children were statistically stronger than the results from the English children, as indicated by the larger effect sizes observed for the main effects of animacy and RC subject. The German children did not, overall, perform better on subject relatives than on object relatives. On the contrary, they performed best on object RCs containing a pronominal RC subject. This provides further evidence against the claim that there is a broad preference for subject relatives over object relatives.

The German children's repetitions of object RCs and their errors were most strongly affected by the constraint of RC subject. The children produced more repetitions and very few errors when the RC subject was a pronoun. As previously noted, the function of a pronominal $\mathrm{RC}$ subject in object relatives is to anchor the head noun in discourse, and they presumably do not incur processing cost because they are more frequent and easier to produce (Arnold, Wasow, Losongco, \& Ginstrom, 2000; Reali \& Christiansen, in press). The German children were more sensitive to the constraint than were the English children, which might reflect word order differences between the two languages. Unlike in English where the word order within an object RC is non-canonical, word order within German subjectand object RCs is invariable with respect to the placement of the verb. 
Therefore in German children do not have to deal with the added ambiguity of variable word order within the RC.

The constraint of animacy affected the German-speaking children's repetitions, but only when the RC subject was a lexical NP. This supports Mak et al.'s (2006) topicworthy account, since children performed better when the head referent of object RCs was inanimate. The fact that animacy only affected repetitions when the RC subject was pronominal is likely to reflect the added value the German children received from pronominal RC subjects. It is conceivable that this constraint freed up enough resources for children to overcome the additional complexity associated with animate head nouns. This interpretation is supported by the children's pattern of errors: both age groups made more ambiguous and unambiguous conversions when the RC subject was a pronoun, but only the 4-year-old children's unambiguous conversions were affected by animacy. This could reflect the possibility that the constraint of animacy is not as strong as the constraint of RC subject.

The German-speaking children's processing of subject relatives was also affected by animacy. In contrast to the English-speaking children, they produced more repetitions when the head referent was inanimate. Additionally, they produced more errors when the head referent was animate. At face value this result could be construed to be inconsistent with Mak et al.'s (2006) topicworthy account, since animate heads should be strongly associated with a subject relative. However, there is an alternative explanation that derives from frequency of distribution and syntactic complexity. Mak et al. (2002) showed that in German written corpora animate and inanimate heads are equally likely in subject RCs. The same is the case in our German child language corpus, where $40 \%$ of head referents in subject RCs were animate and $47 \%$ inanimate (13\% were ambiguous). Since they are equally likely, we argue that children and adults should not be troubled by the animacy of the head when it co-occurs with a nominative marked relative pronoun (recall that relative pronouns are marked for case in German, which often signals the relativised role in the RC). The difference between the inanimate and animate head conditions in the German children's data must therefore be due to the only other difference between the sentence types - the transitivity of the RC. The sentences with inanimate heads contained intransitive RCs and those with animate heads contained transitive RCs. Diessel and Tomasello (2005) showed that German- and English-speaking children performed better on subject relatives that contained intransitive RCs than on those that contained transitive RCs (head nouns were always animate), and we appear to be observing this same effect here.

One apparent problem with this explanation is that the English corpus data for subject relatives are almost identical to the German data (42\% animate heads, $51 \%$ inanimate, $7 \%$ ambiguous), but that this explanation 
does not fit because the English children performed better on the subject RCs that contained animate heads. The clear difference between German and English, however, is that German relative pronouns are case marked and therefore less ambiguous, whereas in English the role of the head noun within the $\mathrm{RC}$ is still fully ambiguous at the relative pronoun. In particular, since an inanimate NP-that combination is a strong cue to an object $\mathrm{RC}$, we may see greater interference in the English data. The suggestion is therefore that the difference between the German- and English-speaking children's performance on subject relatives is due to language-specific influences on their processing of these structures, the ramifications of which are felt downstream when the children were required to produce the RC.

Comparison between Studies $1 \mathrm{~B}$ and $2 \mathrm{~B}$. We compared the results of Studies $1 \mathrm{~B}$ and $2 \mathrm{~B}$ by reanalysing the full data set with language group as a between-subjects variable. First we compared the children's performance on object relatives. Two four-way 2 (age: 3 - vs. 4-year-olds) $\times 2$ (Animacy of head referent: Animate vs. Inanimate $) \times 2$ (RCX subject type: Lexical NP vs. Pronoun) $\times 2$ (Language: English vs. German) ANOVAs were conducted, one by participants $\left(F_{1}\right)$ and one by items $\left(F_{2}\right)$. All the original effects observed in the individual language group analyses were upheld. Additionally, there were some between-language effects. The main effect for language was significant, $F_{1}(1,93)=6.27, p=.014, M S E=.02$ partial $\eta^{2}=.063 ; F_{2}(1$, $48)=4.36, p=.042, M S E=.009$, partial $\eta^{2}=.083$ : the English-speaking children performed significantly better overall than the German-speaking children. The two-way age by language interaction was significant, $F_{1}(1$, $93)=4.76, p=.032, M S E=.02$, partial $\eta^{2}=.049 ; F_{2}(1,48)=7.03, M S E=$ $.009, p=.011$, partial $\eta^{2}=.128$. This effect was due to the fact that, overall, the 3-year-old English-speaking children performed better than the 3-yearold German-speaking children, but that the 4-year-old English- and German-speaking children did not differ from each other. The two-way $\mathrm{RC}$ subject by language interaction was significant, $F_{1}(1,93)=10.7, p=.002$, $M S E=.007$, partial $\eta^{2}=.103 ; F_{2}(1,48)=26.22, p<.001, M S E=.009$, partial $\eta^{2}=.353$. This effect was due to the fact that the German-speaking children showed a greater difference than the English-speaking children in their performance between the object RCs that had lexical NP and pronominal RC subjects. The three-way animacy by RC subject NP by language was also significant, $F_{1}(1,93)=13.11, p<.001, M S E=.002$, partial $\eta^{2}=.124 ; F_{2}(1,48)=5.72, p=.021, M S E=.009$, partial $\eta^{2}=.106$. This effect was due to the fact that although both language groups' performance was affected by the variable of animacy fairly equally, the German children were influenced by the constraint of RC subject much more than were the English-speaking children. The three-way RC subject NP by language by age 
interaction was significant by participants and marginal by items, $F_{1}(1,93)=$ 4.34, $p=.04, M S E=.007$, partial $\eta^{2}=.045 ; \quad F_{2}(1,48)=3.99, p=.052$, $M S E=.009$, partial $\eta^{2}=.077$. This difference was due to the fact that the English children became better at processing object RCs containing lexical NP RC subjects with age, whereas the German children still showed a marked difference between lexical NP and pronominal RC subjects at 4 years. There were no other significant differences between the two language groups.

Next we compared the children's performance on the subject relatives. Two 2 (Age: 3- vs. 4-year-olds) $\times 2$ (Animacy of head referent: animate vs. inanimate) $\times 2$ (language: English vs. German) ANOVAs were conducted, one by participants and one by items. The two-way animacy by language interaction was significant, $F_{1}(1,93)=69.07, p<.001, M S E=.002$, partial $\eta^{2}=.426 ; \quad F_{2}(1,24)=45.87, p<.001, M S E=.01$, partial $\eta^{2}=.657$. As expected, this effect was due to the fact that the English-speaking children performed better on subjects RCs containing animate head referents, whereas the German-speaking children performed better on subject RCs containing inanimate heads. There was no age by language interaction $(F \mathrm{~s}<$ 1); however, the English-speaking children performed better on the subject relatives overall than did the German-speaking children, $F_{1}(1,93)=14.97$, $p<.001, M S E=.01$, partial $\eta^{2}=.139 ; F_{2}(1,24)=16.93, p<.001, M S E=$ .01 , partial $\eta^{2}=.414$.

Overall, the English-speaking children appeared to have some advantage over the German children when tested on both object and subject RCs. We suggest that this is because in English one only has to learn word order regularities to use relative clauses. In German there are many more ways one can go wrong. In particular, one must learn a whole morphological case paradigm for the relative pronoun system.

\section{GENERAL DISCUSSION}

In this paper we explored whether 3-4-year-old English- and Germanspeaking children are sensitive to the same constraints on object relative clause formation and processing as are adult speakers of these languages. The results from two corpora studies and two sentence repetition studies suggest that the children were indeed sensitive to these constraints. Namely, the children performed best when they were tested on object relatives that they most often say and hear: those that have an inanimate head noun and a pronominal RC subject. When these constraints favour object relative formation, the children in our studies performed at least equally well on 
these sentences compared to subject relatives, suggesting that the subjectobject RC asymmetry derives from the violation of constraints on processing rather than constraints on syntactic derivation.

These results raise a number of broad theoretical issues. The first concerns the extent to which there is continuity between the child and adult processing systems. In contrast to early research findings (e.g., Sheldon, 1974; Tavakolian, 1981), our results suggest that there is a good deal of continuity between the processing and production systems of young children and adults. Recent related work has shown that children use the lexical bias of the verb to predict the upcoming structure of a sentence (e.g., Kidd \& Bavin, 2007; Kidd, Lieven, \& Tomasello, 2006; Snedeker \& Trueswell, 2004). Verbs play a central role in sentence meaning, therefore it makes sense that children are sensitive to this information when processing language. The results from the current study show that children are also sensitive to other constraints. More importantly, the results show that children are capable of coordinating multiple constraints on processing and production at the same time. The results are therefore consistent with constraint-based lexicalist approaches to the development of processing, such as Bates and MacWhinney's (1989) Competition Model, and related proposals made by Seidenberg and MacDonald (1999) and Trueswell and Gleitman (2004).

Let us consider what the current results mean within the context of these theoretical proposals. MacDonald (1999) argued that sensitivity to distributional information is an important link between the comprehension and production systems, and the acquisition of language. In particular, MacDonald suggested that distributional regularities that guide performance in comprehension could be due to biases in the sentence production system, and that this distributional information is recorded over the course of an individual's lifetime, throughout acquisition. There is evidence in the adult literature to suggest that sentence production is lemma-driven and incremental (Ferreira, 1996; Levelt, 1989). Furthermore, there is evidence to suggest that the structural choices speakers make in production result from the interplay between lexical availability and syntactic production mechanisms (e.g., Arnold et al., 2000; Bock, 1986, 1987; Ferreira \& Dell, 2000). We suggest that the results of the present research support such an approach.

Consider the constraint of the animacy of the head referent on object RC formation. We follow Fox and Thompson (1990) and Mak et al. (2006) in arguing that this is a semantic constraint on object relative formation that can be explained in terms of preferred argument structure: inanimate nouns make bad agents and, consistent with general usage patterns, are most often themes of conversation. Therefore in cases of relativisation, when inanimate nouns are in focus, the head noun is most often likely to occupy the object role within the relative clause. That is, an inanimate head noun primes the use of an object relative clause. Conversely, since animate nouns are most 
often agents, they prime the use of a subject relative clause when they occur in a NP-relative pronoun sequence.

Warren and Gibson (2002) suggest that discourse-old referents in the subject slot of the RC do not require the postulation of new referents and therefore place fewer demands on processing resources. Our data do not argue against this proposal, but we emphasise that this explanation partially isolates this constraint from its discourse function - to anchor the head referent with respect to the background information contained in the relative clause. Therefore, although what Warren and Gibson (2002) claim may be true in a computational sense, it tells us nothing about how children acquire the constraint and why they use it. Our corpora data suggest that children use discourse new referents in the subject slot of an object RC on only a minority of occasions, suggesting that, like adults, their productions are constrained by the knowledge that (a) relative clauses often encode old information, (b) previously mentioned referents can be referred to using anaphoric pronouns, and (c) pronouns most often stand for subjects (Du Bois, 1987). We suggest that these discourse-based facts, along with the fact that given information is more accessible and are thus easier to produce (Arnold et al., 2000), lead to the distributional patterns found in our corpora studies.

As noted earlier, our sentence repetition data do not wholly speak to this discourse-based explanation of the RC-subject effect, since our experimental task did not really manipulate the discourse status of the RC-subject beyond using the grammatical conventions that mimic these phenomena (i.e., lexical NPs and pronouns). What our experimental data do show, however, is that children were better at repeating those sentences that contained pronominal $\mathrm{RC}$ subjects than those that contained lexical NPs. This result suggests that children are sensitive to distributional patterns of their input language and use them to process and produce language. Therefore, following MacDonald (1999), we suggest that Warren and Gibson's (2002) argument that discourseold subjects ease processing in object relatives can be explained by usage patterns recorded by the processing system over developmental time (for a similar argument see Reali \& Christiansen, in press). These usage patterns predict performance on a range of experimental tasks, as in our sentence repetition data, and also in adult reading time and ERP studies (e.g., Mak et al., 2002, 2006; Reali \& Christiansen, in press; Traxler et al., 2002, 2005; Warren \& Gibson, 2002, 2005; Weckerly \& Kutas, 1999).

What is the mechanism by which children learn these contingencies? The differences we observed in the children's processing of object relatives rely on children detecting the variable effect of the constraints on distributional contingencies. That is, it requires sensitivity to the distribution of thematic roles and NP types that inhabit these roles, and it requires sensitivity to the devices by which clauses are linked. There are a number of theoretical 
proposals in the literature that argue that children perform a distributional analysis of their input. Maratsos and Chalkley (1980) first discussed this possibility with respect to language learning, and it is now embodied in theories of acquisition such as Tomasello's (2003) constructivist approach ('functional distributional analysis'), emergentist approaches such as those outlined by Seidenberg and MacDonald (1999), see also MacDonald, 1999), MacWhinney (1998), and O'Grady (2005), and Trueswell and Gleitman's (2004) constraint-based lexicalist approach. We do not attempt to differentiate between these approaches here, but simply point out that all assume a distributional learning mechanism as the foundation for pattern detection. There is a body of research that suggests that even very young children are adept at performing distributional analyses over formal sequences that lack semantic content (Marcus, Vijayan, Bandi Rao, \& Vishton, 1999; Saffran, Aslin, \& Newport, 1996), a capacity that seems to be shared by our primate cousins (Newport, Hauser, Spaepen, \& Aslin, 2004; Ramus, Hauser, Miller, Morris, \& Mehler, 2000). Analysing linguistic regularities devoid of meaning only allows the child a foot in the door, however, and once children learn the meanings of words they will soon have to learn the relationships between words and their functions. The results of the present research suggests that even at 3 years children are sensitive to the distribution of form and function in the same subtle and sophisticated ways as are adults.

What our data do not show, however, are clear developmental differences in the acquisition of the individual constraints that we tested. We can only speculate why this is the case. One possible reason for this is that, following Reali and Christiansen (in press), high frequency inanimate NP-that-pro collocations are learned by children as chunks and are implemented by the parser as wholistic forms. An alternative explanation is that the two constraints are equally available in the ambient language. In support of this explanation we point out that our corpus studies showed an overwhelming skew in favour of object relatives that contained both inanimate head and pronominal RC subjects. However, the children's repetitions were affected most strongly by the constraint of $\mathrm{RC}$ subject type in both languages. Future studies could investigate this line of explanation further by testing the relationship between child-directed speech and children's productions, and children's experimental data.

Regardless of the precise developmental origin of our effects, the data point to a very sophisticated learner that is highly attuned to the regularities of the input language on a number of levels. The previous studies that have investigated children's knowledge and processing of relative clauses appear to have underestimated the extent of children's ability because they did not test children on the appropriate test sentences. Our results show that children do 
not process relative clauses in a manner different from adults, as was the standard assumption for many years in the literature (for a discussion see Kidd \& Bavin, 2002). Instead, children appear to process relative clauses in a qualitatively similar manner to adults, suggesting a large degree of continuity between the child and adult processing and production systems.

Manuscript received June 2006

Revised manuscript received November 2006

First published online February 2007

\section{REFERENCES}

Arnold, J. E., Wasow, T., Losongco, T., \& Ginstrom, R. (2000). Heaviness vs. Newness: The effects of structural complexity and discourse status on constituent ordering. Language, 76, 28-55.

Arnon, I. (2005). Relative clause acquisition in Hebrew: towards a processing-oriented account. In A. Brugos, M. Clark-Cotton, \& S. Ha (Eds.), Proceedings of the $29^{\text {th }}$ Annual Boston Conference on Language Development (pp. 37-48). Somerville, MA: Cascadilla Press.

Bates, E., \& MacWhinney, B. (1982). Functionalist approaches to grammar. In E. Wanner \& L. Gleitman (Eds.), Language acquisition: The state of the art (pp. 173-218). New York: Cambridge University Press.

Bates, E., \& MacWhinney, B. (1989). Functionalism and the competition model. In Brian MacWhinney \& Elizabeth Bates (Eds.), The crosslinguistic study of sentence processing (pp. 373). Cambridge, UK: Cambridge University Press.

Bever, T. (1970). The cognitive basis of linguistic structures. In J. R. Hayes (Ed.), Cognition and the development of language (pp. 279-362). New York: John Wiley \& Sons.

Bever, T. (1974). The ascent of the specious, or there's a lot we don't know about mirrors. In D. Cohen (Ed.), Explaining linguistic phenomena (pp. 173-200). Washington, DC: Hemisphere.

Bloom, L. (1973). One word at a time: The use of single word utterances. The Hague: Mouton.

Bock, J. K. (1986). Meaning, sound, and syntax: Lexical priming in sentence production. Journal of Experimental Psychology: Learning, Memory, and Cognition, 12, 575-586.

Bock, J. K. (1987). An effect of the accessibility of word forms on sentence structures. Journal of Memory and Language, 26, 119-137.

Brandt, S. (2004). The acquisition of relative clauses in German and English. Unpublished MA thesis, Leipzig: University of Leipzig.

Bybee, J. (2002). Sequentiality as the basis for constituent structure. In T. Givón \& B. Malle (Eds.), The evolution of language out of pre-language (pp. 107-132). Philadelphia, PA: John Benjamins.

Bybee, J. (2006). From usage to grammar: The mind's response to repetition. Language, 82, 529551.

Brown, R. (1973). A first language. Cambridge, MA: Harvard University Press.

Córrea, L. M. (1995). An alternative assessment of children's comprehension of relative clauses. Journal of Psycholinguistic Research, 24, 183-203.

Diessel, H. (2004). The acquisition of complex sentences. Cambridge, UK: Cambridge University Press.

Diessel, H., \& Tomasello, M. (2000). The development of relative clauses in spontaneous child speech. Cognitive Linguistics, 11, 131-151.

Diessel, H., \& Tomasello, M. (2005). A new look at the acquisition of relative clauses. Language, 81, $882-906$.

Du Bois, J. W. (1987). The discourse basis of ergativity. Language, 63, 805-855. 
Ferreira, V. S. (1996). Is it better to give than to donate? Syntactic flexibility in language production. Journal of Memory and Language, 35, 724-755.

Ferreira, V. S., \& Dell, G. S. (2000). Effect of ambiguity and lexical availability on syntactic and lexical production. Cognitive Psychology, 40, 296-340.

Fox, B., \& Thompson, S. (1990). A discourse explanation of the grammar of relative clauses in English conversation. Language, 66, 856-870.

Friedmann, N., \& Novogrodsky, R. (2004). The acquisition of relative clause comprehension in Hebrew: A study of SLI and normal development. Journal of Child Language, 31, 661-681.

Gibson, E. (1998). Linguistic complexity: locality of syntactic dependencies. Cognition, 68, 1-79.

Goodluck, H., \& Tavakolian, S. (1982). Competence and processing in children's grammar of relative clauses. Cognition, 11, 1-27.

Gordon, P. C., Hendrick, R., \& Johnson, M. (2001). Memory interference during language processing. Journal of Experimental Psychology: Learning, Memory, and Cognition, 27, 14111423.

Hamburger, H., \& Crain, S. (1982). Relative acquisition. In S. Kuczaj (Ed.), Language development, vol. 1: syntax and semantics (pp. 245-274). Hillsdale, NJ: Erlbaum.

Keenan, E., \& Comrie, B. (1977). Noun phrase accessibility and universal grammar. Linguistic Inquiry, 8, 63-99.

Kidd, E. (2003). Relative clause comprehension revisited: commentary on Eisenberg (2002). Journal of Child Language, 30, 671-679.

Kidd, E., \& Bavin, E. L. (2002). English-speaking children's understanding of relative clauses: Evidence for universal-cognitive and language-specific constraints on development. Journal of Psycholinguistic Research, 31, 599-617.

Kidd, E., \& Bavin, E. L. (2007). Lexical and referential influences on on-line spoken language comprehension: A comparison of adults and primary school-age children. First Language, 27, 29-52.

Kidd, E., Lieven, E., \& Tomasello, M. (2006). Examining the role of lexical frequency in children's acquisition and processing of sentential complements. Cognitive Development, 21, 93-107.

Levelt, W. J. M. (1989). Speaking: From intention to articulation. Cambridge, MA: MIT Press.

Lust, B., Flynn, S., \& Foley, C. (1996). What we know about what they say: Elicited imitation as a research method. In D. McDaniel, C. McKee, \& H. Cairns (Eds.), Methods for assessing children's syntax (pp. 55-76). Cambridge, MA: MIT Press.

MacDonald, M. C. (1999). Distributional information in language comprehension, production, and acquisition: Three puzzles and a moral. In B. MacWhinney (Ed.), The emergence of language (pp. 177-196). Mahwah, NJ: Lawrence Erlbaum Associates Inc.

MacDonald, M. C., Pearlmutter, N., \& Seidenberg, M. (1994). Lexical nature of syntactic ambiguity resolution. Psychological Review, 101, 676-703.

MacWhinney, B. (1998). Models of the emergence of language. Annual Review of Psychology, 49, 199-227.

MacWhinney, B. (Ed.) (2000). The CHILDES Project: Tools for analysing talk (Vol. 1). Mawah, NJ: Lawrence Erlbaum Associates Inc.

Mak, W. M., Vonk, W., \& Schriefers, H. (2002). The influence of animacy on relative clause processing. Journal of Memory and Language, 47, 50-68.

Mak, W. M., Vonk, W., \& Schriefers, H. (2006). Animacy in relative clause processing: The hiker that rocks crush. Journal of Memory and Language, 54, 466-490.

Maratsos, M., \& Chalkley, M. (1980). The internal language of children's syntax. In K. Nelson (Ed.), Children's language (Vol. 2) (pp. 127-214). New York: Gardner Press.

Marcus, G. F., Vijayan, S., Bandi Rao, S., \& Vishton, P. M. (1999). Rule learning in seven-monthold infants. Science, 283, 77-80. 
Miyamoto, E., \& Nakamura, M. (2003). Subject/Object asymmetries in the processing of relative clauses in Japanese. In G. Garding \& M. Tsujimura (Eds.), Proceedings of WCCFL, 22, $342-$ 355.

Newport, E. L., Hauser, M. D., Spaepen, G., \& Aslin, R. N. (2004). Learning at a distance II: Statistical learning of non-adjacent dependencies in a non-human primate. Cognitive Psychology, 49, 85-117.

O'Grady, W. (2005). Syntactic carpentry: An emergentist approach to syntax. Mawah, NJ: Lawrence Erlbaum Associates Inc.

Potter, M. C., \& Lombardi, L. (1990). Regeneration in the short term recall of sentences. Journal of Memory and Language, 29, 633-654.

Potter, M. C., \& Lombardi, L. (1998). Syntactic priming in immediate recall of sentences. Journal of Memory and Language, 38, 265-282.

Ramus, F., Hauser, M. D., Miller, C. T., Morris, D., \& Mehler, J. (2000). Language discrimination by human newborns and cotton-top tamarin monkeys. Science, 288, 349-351.

Reali, F., \& Christiansen, M. H. (in press). Processing of relative clauses is made easier by frequency of occurrence. Journal of Memory and Language.

Saffran, J., Aslin, R., \& Newport, E. (1996). Statistical learning by 8-month-old infants. Science, 274, 1926

Schriefers, H., Friederici, A. D., \& Kühn, K. (1995). The processing of locally ambiguous relative clauses in German. Journal of Memory and Language, 34, 499-520.

Seidenberg, M., \& MacDonald, M. C. (1999). A probabilistic constraints approach to language acquisition and processing. Cognitive Science, 23, 569-588.

Sheldon, A. (1974). The role of parallel function in the acquisition of relative clauses in English. Journal of Verbal Learning and Verbal Behavior, 13, 272-281.

Slobin, D. I., \& Bever, T. (1982). Children use canonical sentence schemas: A cross-linguistic study of word order and inflection. Cognition, 12, 229-265.

Snedeker, J., \& Trueswell, J. C. (2004). The developing constraints on parsing decisions: The role of lexical-biases and referential scenes in child and adult sentence processing. Cognitive Psychology, 49, 238-299.

Suppes, P. (1974). The semantics of children's language. American Psychologist, 88, 103-114.

Tavakolian, S. L. (1981). The conjoined-clause analysis of relative clauses. In S. L. Tavakolian (Ed.), Language acquisition and linguistic theory (pp. 167-187). Cambridge, MA: MIT Press.

Tomasello, M. (2003). Constructing a language: A usage-based theory of language acquisition. Cambridge, MA: Harvard University Press.

Townsend, D. J., \& Bever, T. (2001). Sentence comprehension: The integration of habits and rules. Cambridge, MA: MIT Press.

Traxler, M. J., Morris, R. K., \& Seely, R. E. (2002). Processing subject and object relative clauses: Evidence from eye movements. Journal of Memory and Language, 47, 69-90.

Traxler, M. J., Williams, R. S., Blozis, S. A., \& Morris, R. K. (2005). Working memory, animacy, and verb class in the processing of relative clauses. Journal of Memory and Language, 53, 204224.

Trueswell, J. C., \& Gleitman, L. (2004). Children's eye-movements during listening: Developmental evidence for a constraint-based theory of sentence processing. In J. M. Henderson \& F. Ferreira (Eds.), Interface of vision, action, and language (pp. 319-346). NY: Psychology Press.

Warren, T., \& Gibson, E. (2002). The influence of referential processing on sentence complexity. Cognition, 85, 79-112.

Warren, T., \& Gibson, E. (2005). Effects of NP type in reading cleft sentences in English. Language and Cognitive Processes, 20, 751-767.

Weckerly, J., \& Kutas, M. (1999). An electrophysiological analysis of animacy effects in the processing of object relative sentences. Psychophysiology, 36, 599-570. 
Sentences for Study 1B

\section{APPENDIX A}

Object-rel/animate head/lexical NP (Obj-A-NP)

(1) This is the boy [that the girl teased _ at school yesterday].

(2) Here is the girl [that the lady saw _ on the bus today].

(3) That is the man [that the dog bit _ at the park yesterday].

(4) There is the girl [that the cat licked_ in the garden today].

Object-rel/inanimate head/lexical NP (Obj-I-NP)

(5) This is the fence [that the dog jumped _ at the park yesterday].

(6) Here is the food [that the cat ate _ in the kitchen today].

(7) That is the pen [that the boy used _ at school yesterday].

(8) There is the ball [that the girl threw _ in the playground today].

Object-rel/animate head/pronoun (Obj-A-Pro)

(9) This is the boy [that you saw _ at the shop on Saturday].

(10) Here is the girl [that you pushed _ on the bus this morning].

(11) That is the dog [that you stroked _ in the park yesterday].

(12) There is the hippo [that you fed _ by the tree yesterday].

Object-rel/inanimate head/pronoun (Obj-I-Pro)

(13) This is the football [that you kicked _ in the garden yesterday].

(14) Here is the glass [that you broke _ in the kitchen today].

(15) That is the toy [that you bought _ at the market today].

(16) There is the book [that you read _ in the front room last night].

Subject-rel/animate head (Sub-A)

(17) This is the man [that _ saw the boy at football practice].

(18) Here is the lady [that _ helped the girl at school today].

(19) That is the boy [that _ hit the cricket ball over the fence].

(20) There is the hippo [that _ chased the people at the zoo].

Subject-rel/inanimate head (Sub-I)

(21) This is the stick [that _ fell from the tree in the garden].

(22) That is the pen [that _ ran out of ink at school today].

(23) Here is the plant [that _ grew in the garden last summer].

(24) There is the toy [that _ broke on Christmas Day last year]. 


\section{APPENDIX B}

TABLE A

Ranked means and mean differences for each experimental condition in Study 1B

\begin{tabular}{|c|c|c|c|c|c|c|}
\hline & $X$ & & & $X_{i}-X_{j}$ & & \\
\hline Subj-A & .615 & & & & & \\
\hline Obj-I-Pro & .610 & .005 & & & & \\
\hline Obj-A-Pro & .492 & $.123 \sim$ & .118 & & & \\
\hline Subj-I & .452 & $.163^{*}$ & $.158 *$ & .04 & & \\
\hline Obj-I-NP & .441 & $.174 *$ & $.169 *$ & .051 & .011 & \\
\hline Obj-A-NP & .406 & $.209^{*}$ & $.204^{*}$ & .086 & .046 & .035 \\
\hline
\end{tabular}

TABLE B

Ranked means and mean differences for each experimental condition in Study 2B

\begin{tabular}{|c|c|c|c|c|c|c|}
\hline & $X$ & & & $X_{i}-X_{j}$ & & \\
\hline Obj-A-Pro & .557 & & & & & \\
\hline Obj-I-Pro & .531 & .026 & & & & \\
\hline Subj-I & .477 & .08 & .054 & & & \\
\hline Obj-I-NP & .281 & $.276^{*}$ & $.25^{*}$ & $.196^{*}$ & & \\
\hline Subj-A & .216 & $.296^{*}$ & $.27 *$ & $.216^{*}$ & .02 & \\
\hline Obj-A-NP & .154 & $.403 *$ & $.377^{*}$ & $.323^{*}$ & $.127 *$ & .107 \\
\hline
\end{tabular}

$* p<.05$.

\section{APPENDIX C}

Sentences for Study 2B (with English glosses and translation)

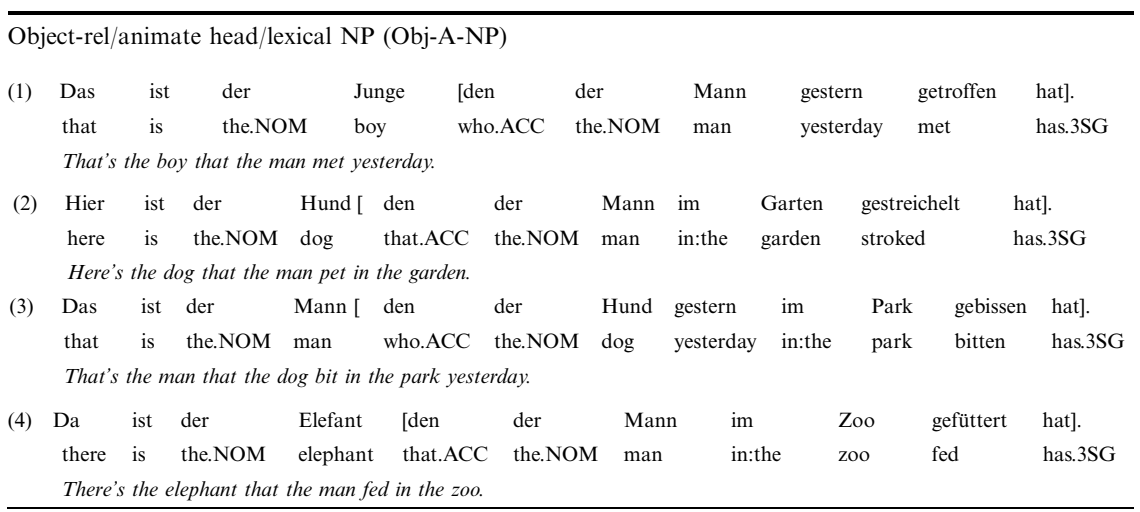


Object-rel/inanimate head/lexical NP (Obj-I-NP)

(5) Das ist der Ring [ den der Mann heute Morgen gesucht hat]. that is the.NOM ring that.ACC the.NOM man today morning looked:for has.3SG That's the ring that the man was looking for this morning.

(6) Hier ist der Kuchen [ den der Mann heute gebacken hat here is the.NOM cake that.ACC the.NOM man today baked has.3SG Here's the cake that the man baked today.

(7) Das ist der Stift [ den der Junge zu Hause benutzt hat $]$. that is the.NOM pen that.ACC the.NOM boy at home used has.3SG That's the pen that the boy used at home.

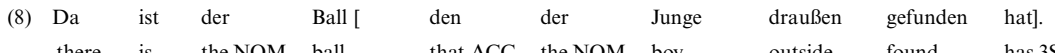
there is the.NOM ball that.ACC the.NOM boy outside found has.3SG There's the ball that the boy found outside.

Object-rel/inanimate head/pronoun (Obj-A-Pro)
(9) $\mathrm{Da}$ ist der Mann [ den $\mathrm{du}$ gestern im Laden gesehen hast]. there is the.NOM man who.ACC you.NOM yesterday at:the shop seen have.2SG There's the man that you saw at the shop yesterday.
(10) Das ist der Junge [ den ich gestern im Park gesucht habe]. that is the.NOM boy who.ACC I.NOM yesterday in:the park looked:for have.1SG That's the boy that I was looking for in the park yesterday.
(11) Hier ist der Hund [ den du gestern im Garten gestreichelt hast]. here is the.NOM dog that.ACC you.NOM yesterday in:the garden stroked have.2SG Here's the dog that you pet in the garden yesterday.
(12) $\mathrm{Da}$ ist der Bär [ den ich gestern im Zoo gefüttert habe] there is the.NOM bear that.ACC I.NOM yesterday in:the zoo fed have.1SG There's the bear that I fed in the zoo yesterday.

Object-rel/animate head/pronoun (Obj-I-Pro)

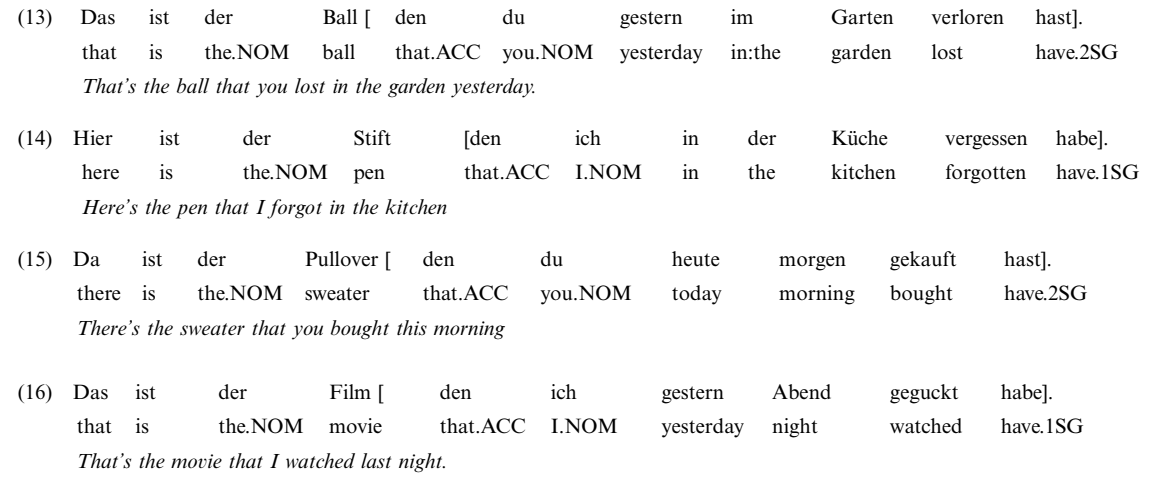


APPENDIX C (Continued)

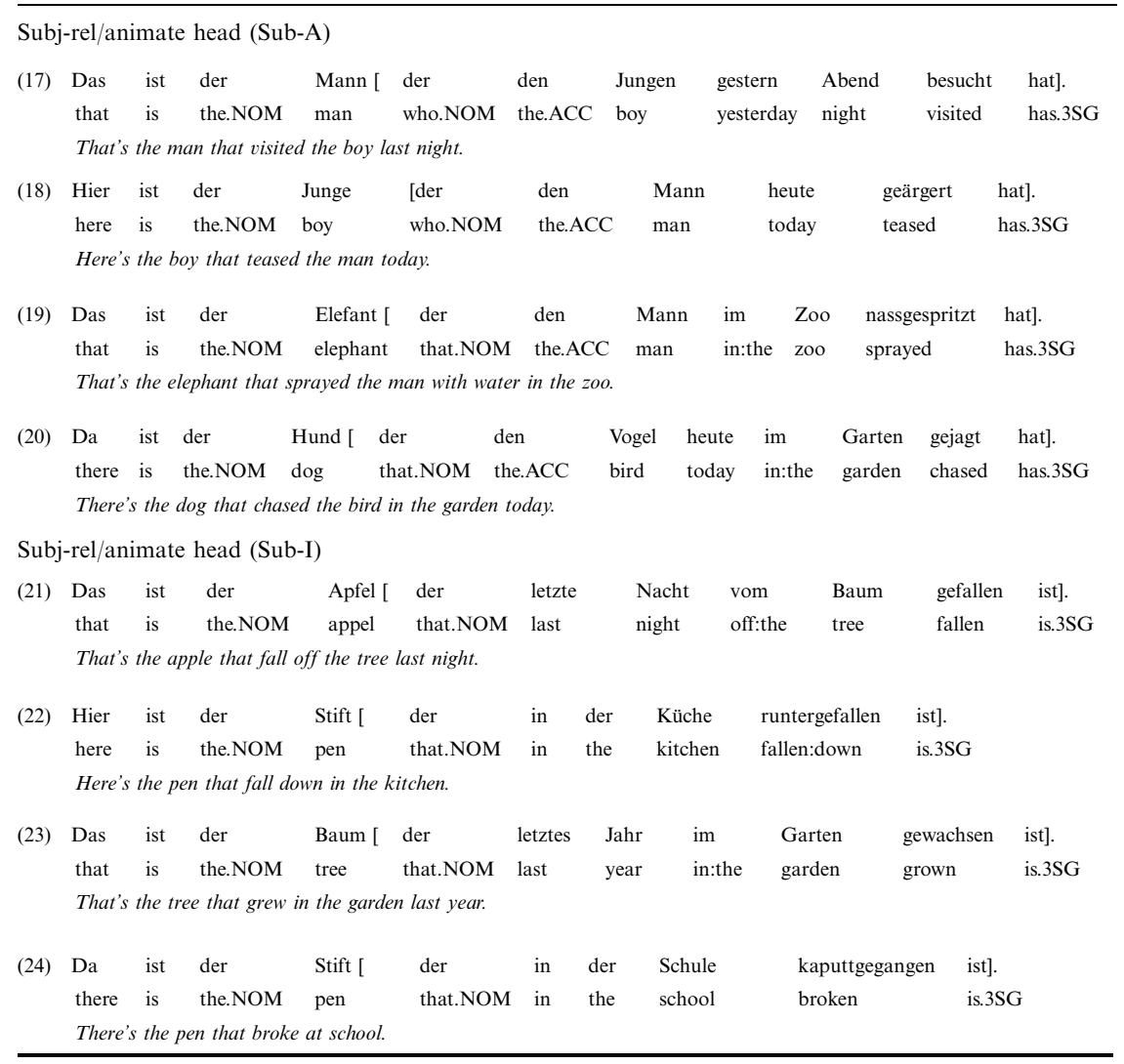

